area lies within the Mamirauá and Amanã Sustainable Development Reserves, which are part of the Amazon Biosphere Reserve.

Between December 2013 and January 2015 we captured and returned 31 yellow-footed tortoises in this area. Eight tortoises were found at the peak of the flood, a period with a minimum water depth of $2 \mathrm{~m}$, during which searches are only possible by canoe. Five of these tortoises were sheltering under branches and trunks and three were floating in the flooded forest. In monitoring this area during 2003-2014 we also recorded the hunting of at least 200 yellow-footed tortoises by local people.

Our findings suggest that the tortoises recorded are members of a population inhabiting the Amazonian várzea. The yellow-footed tortoise is one of the most hunted and traded species in Amazonia, highly prized as game meat and as a pet, and is consequently declining in several areas. As the only strictly terrestrial animal in the várzea, this tortoise is important for the subsistence and income of residents.

Our monitoring has shown that hunting of the yellowfooted tortoise in the várzea is most intense during the flooding season because the tortoises are more detectable when the water is high. The ease of detecting tortoises during this time also results in the capture of young tortoises, an age class normally protected in non-flooded forests because of the difficulty of detecting them.

Although categorized as Vulnerable on the IUCN Red List and included on Appendix II of CITES, the yellowfooted tortoise has rarely been considered in conservation projects, mainly because of the difficulty of detecting this species. Strengthening our knowledge of the major threats faced by tortoises in the várzea is the first step towards developing conservation and sustainable use strategies for this threatened species in this particular Amazonian wetland.

ThaÍs QueIROZ MorCatTy and JoÃo ValseCCHI Research Group on Terrestrial Vertebrate Ecology, Mamirauá Sustainable Development Institute, Tefé, Amazonas, Brazil

E-mail thais.morcatty@mamiraua.org.br

\section{Long-distance dispersal of an Amur tiger indicates potential to restore the North-east China/Russian Tiger Landscape}

Dispersal plays a key role in spatial structuring of populations and has implications for managing top predators, especially those that are elusive and live at naturally low densities. The Amur tiger Panthera tigris altaica occurs in two populations. The Sikhote-Alin population in Russia lies north-east of a highway and train corridor running north and north-west of Vladivostok. The second population, Hunchun-Southwest Primorsky, is south-west of this corridor, in the c. $3,500 \mathrm{~km}^{2}$ Land of the Leopard National
Park, Russia, and the $1,500 \mathrm{~km}^{2}$ Hunchun Reserve, China. Given the low density of tigers in the region (one breeding female per $250 \mathrm{~km}^{2}$ ) this second population is at a viability threshold. To address the threat of small population size the Chinese government has proposed a multi-stage expansion of habitat for this population to create a North-east China/ Russian Tiger Landscape. This landscape comprises a complex of intact, healthy forests and forests with intensive livestock grazing and timber harvest, interspersed with rural villages, agricultural lands and medium and large urban centres.

The extent to which this patchwork of land uses can support a viable population of tigers is unknown. Can more intensive regional management create a tiger-permeable landscape that will increase population size, genetic connectivity and viability? Nine years of data from a grid of $>500$ camera-traps covering c. $6,000 \mathrm{~km}^{2}$ in Hunchun, Wangqing and Huangnihe, China, provide insights into the natural history of tigers that suggest potential exists for creating a second viable population of tigers in North-east China and neighbouring habitat in Russia. This camera-trap monitoring network has produced a photo/video database of $>1,000$ images of $30+$ distinct individual tigers. Here we report a long-distance natal dispersal event that indicates the current land-use matrix may serve as the basis for the long-term recovery of tigers in North-east China if management is improved to favour a tigerpermeable landscape.

Male T16 was first camera-trapped as a subadult (>18 months old) on 10 July 2014 in Laoyeling Nature Reserve, Heilongjiang Province, China, $10 \mathrm{~km}$ from the Russian border. On 1 September 2014 he travelled east to Tianqiaoling village, Jilin Province, $120 \mathrm{~km}$ from Laoyeling, where he was photographed and video-captured at several sites. Over a period of c. 15 days he killed four cattle. By 30 September 2014 he had dispersed $135 \mathrm{~km}$ further west. From October 2014 to June 2015 he killed 10 livestock in this new area $255 \mathrm{~km}$ from Laoyeling Nature Reserve. His dispersal route required moving through narrow habitat corridors and areas of intensely used forest. He has remained in the same area for the past 9 months and may be attempting to establish a breeding territory or a temporary home range in Huannihe Reserve.

Telemetry and camera trap studies have shown that young tigers have the ability to disperse long distances from their natal areas at 19-28 months old as they search for vacant territories (Behaviour, 124, 165-195). Male T16 moved through a series of large forest patches and habitat corridors to c. $270 \mathrm{~km}$ from where he was first trapped. The quality of habitat in this landscape could be improved by reducing livestock grazing and other forest practices such as forest frog farming. Further studies are needed to understand the nature and extent of the forest corridors required for dispersal of tigers at a landscape scale, but this example 
of a tiger dispersing and settling far from its natal area on the Russian border provides support for the current plan to establish a North-east China/Russian Tiger Landscape.

Tianming Wang, Limin Feng, PU Mou and JiANPING Ge College of Life Sciences, Beijing Normal University, Beijing, China E-mailwangtianming@bnu.edu.cn

CHeNG LI Jilin Provincial Huangnihe Nature Reserve, Huangnihe Town, China

JAMES L.D. SMITH Department of Fisheries, Wildlife and Conservation Biology, University of Minnesota, St Paul, Minnesota, USA

\section{Conserving large mammals in partnership with private landowners in Assam, north-east India}

Conservationists are looking increasingly at lands outside protected areas to serve as secondary habitat or dispersal conduits for threatened species. In India, where protected areas are generally small, private landholdings can enhance the viability of wildlife populations. Research carried out by the Wildlife Conservation Society, India Program (WCS India) in north-east India has suggested that for conflictprone species such as the Asian elephant, private land does not serve as primary habitat but could facilitate connectivity. Building upon this finding, WCS India has initiated a connectivity project-predominantly in tea plantations, paddy fields and areas of human habitationbetween Kaziranga National Park and the hills of Karbi Anglong, Assam. The landscape is a unique floodplain ecosystem wherein animals move seasonally between inundated floodplains of Kaziranga and the higher reaches of Karbi Anglong.

In recognition of the potential conservation value of tea plantations, WCS India and Balipara Tract and Frontier Foundation have been working with six plantations, two of which are managed by Amalgamated Plantations Private Ltd, to foster their role as wildlife movement routes. Amalgamated Plantations Private Ltd Foundation, keen to form a model for conservation in tea plantations through adoption of wildlife-friendly management practices, supports the collaborative project initiated by WCS India and Balipara Tract and Frontier Foundation. Amalgamated Plantations Private Ltd Foundation has also tentatively set aside land in plantations between Kaziranga and Karbi Anglong for wildlife habitat and movement.

WCS India is conducting research to assess the conservation value of these lands for mammals. Initial surveys, during January-April 2015, with support from the Department of Science and Technology (Government of India), WCS New York and the Amalgamated Plantations Private Ltd Foundation, indicate that multiple species, including barking deer, leopards and elephants, use tea plantations. Meetings have been held with managers of all six plantations, and further investigations are underway to identify management practices that could sustain or enhance wildlife movement through tea plantations. Through these efforts, organizations involved in this programme aim to integrate scientific findings into decision-making in a manner that serves both wildlife conservation and human livelihood needs.

Divya VASUdEV and VARUN R. Goswami Wildlife Conservation Society, India Program, Bangalore, India

E-mail vasudev.divya@gmail.com

RoBin EASTMENT Balipara Tract and Frontier Foundation, Balipara, Assam, India

\section{Media workshops to improve reporting of human-wildlife interactions}

Interactions between people and wildlife are a common occurrence in many parts of India and much of South Asia. Large mammals that frequent human-inhabited areas are typically depicted in the media as fearsome and dangerous, increasing fear of wild animals and potentially instigating negative attitudes towards wildlife. Heightened antagonism towards wildlife also pressurizes park managers to take action when wildlife shares space with people. One common intervention is translocation of so-called problem leopards, which, as research conducted by the Wildlife Conservation Society, India Program (WCS India) has shown, can actually increase conflict with people near release sites.

In April 2015 WCS India held collaborative workshops to increase the sensitivity of media personnel in reporting human-wildlife interactions. This was part of a series of seven workshops conducted across multiple high-conflict states in India over the last 2 years, supported by the Rufford Foundation and WCS New York. Participants numbered more than 200, and included park managers involved in mitigating conflict, local conservation NGOs, and journalists from the English and local-language media. The workshops focused on the positive impacts that media reporting can have on the nature of human-wildlife interactions through shaping public perception of wildlife and influencing the way we deal with wild animals that occur in human-use lands. Workshop content included research findings on conflict-prone mammals from WCS India and other organizations (including the Nature Conservation Foundation and Centre for Conservation and Research); novel mitigation methods detailed by conservation practitioners; and a media perspective on human-wildlife conflict and how the media can reduce sensationalism and make people more aware of the complex nature of this issue. 